\title{
Strain Relief Device
}

National Cancer Institute

\section{Source}

National Cancer Institute. Strain Relief Device. NCI Thesaurus. Code C50193.

A structure designed to function with a connector to prevent damage to a hose or cable from excess flexing. 